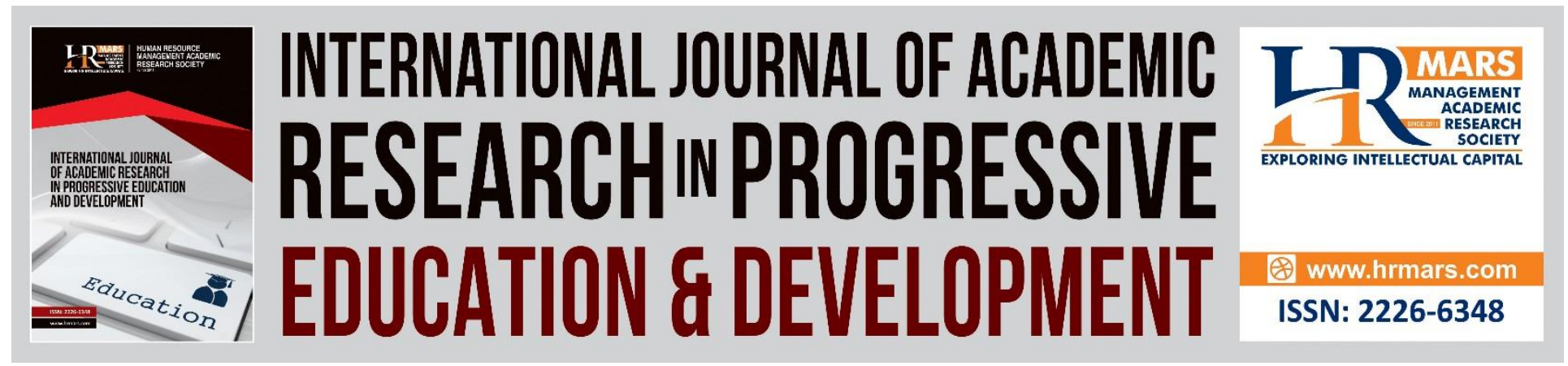

\title{
Language-Based Approach as a Trend to Enhance Pupil's Interest in Children's Literature
}

Atiqah Ab Hamid \& Azlina Abdul Aziz

To Link this Article: http://dx.doi.org/10.6007/IJARPED/v9-i2/7346

DOI:10.6007/IJARPED/v9-i2/7346

Received: 15 April 2020, Revised: 13 May 2020, Accepted: 29 May 2020

Published Online: 30 June 2020

In-Text Citation: (Hamid \& Aziz, 2020)

To Cite this Article: Hamid, A. A., \& Aziz, A. A. (2020). Language-Based Approach as a Trend to Enhance Pupil's Interest in Children's Literature. International Journal of Academic Research in Progressive Education and Development, 9(2), 318-333.

Copyright: (C) 2020 The Author(s)

Published by Human Resource Management Academic Research Society (www.hrmars.com)

This article is published under the Creative Commons Attribution (CC BY 4.0) license. Anyone may reproduce, distribute, translate and create derivative works of this article (for both commercial and non-commercial purposes), subject to full attribution to the original publication and authors. The full terms of this license may be seen

at: http://creativecommons.org/licences/by/4.0/legalcode

Vol. 9(2) 2020, Pg. 318 - 333

http://hrmars.com/index.php/pages/detail/IJARPED

JOURNAL HOMEPAGE

Full Terms \& Conditions of access and use can be found at

http://hrmars.com/index.php/pages/detail/publication-ethics 


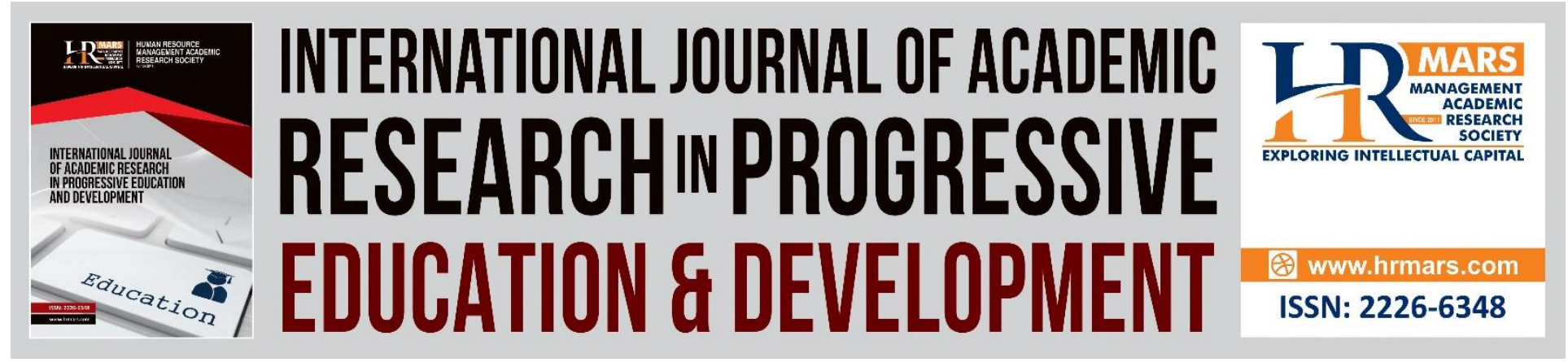

\title{
Language-Based Approach as a Trend to Enhance Pupil's Interest in Children's Literature
}

\author{
Atiqah Ab Hamid ${ }^{1}$ \& Azlina Abdul Aziz ${ }^{2}$ \\ Faculty of Education, Universiti Kebangsaan Malaysia, Bangi, Selangor, Malaysia ${ }^{12}$ \\ Email: atiqah_nohara@yahoo.com ${ }^{1}$ azlina1@ukm.edu.my²
}

\begin{abstract}
Children's literature is one of the government's endeavors that have been put forward to draw in learners to learn and to give them a superior outsight of the significance of English in the Malaysian education system. Notwithstanding, pupils at primary schools who study the second language are having difficulties engaging in literature classroom activities. This research aims to discover the possible outcome of using the language-based approach to enhance pupils' interest in literature with the use of literary text, The King of Kites. A case study that includes the qualitative method was completed to explore the effectiveness of a language-based approach in enhancing Year 4 pupils' interest in children's literature. The population of this study was a class of Year of 10-year-old primary school pupils from Endau, Johor. Therefore, 30 pupils became participants. The data were collected using pre- and post-test as well as a questionnaire. Later, the data was analysed with the use of descriptive and inferential methods. The pre- and post-test and questionnaire tests showed a significant improvement in pupils' interest in children's literature. The findings proved that the use of the language-based approach is effective in enhancing pupils' interest in children's literature in classroom practice. Hence, English teachers are suggested to incorporate the language-based approach into their teaching as it serves numerous benefits to the pupils.
\end{abstract}

Keywords: Children's Literature, Language-Based Approach, Interest.

\section{Introduction}

In the study of literature, past researchers just as teachers acknowledge as true that the incorporation of language study plays out an essential position as it is one of the crucial aspects and intently associated with this subject. Albeit this topic, in particular, is not regularly discussed as regards language teaching and learning as a coherent curriculum branch, teachers and scholars continue to claim that language and literature are closely linked and can be integrated. However, pupils at primary schools who study the second language are having difficulties engaging in literature classroom activities. Malaysia's Ministry of Education has acknowledged the significance of learning literature in the context of the Malaysian classroom 
(Subarna \& Ganakumaran, 2008). Conversely, due to the structural complexity of literature itself as well as its superior use of language, pupils appear to display an absence of interest in learning this subject. Pupils view literature as a burdening subject and the contents exceed their comprehension and understanding ability. For certain reasons, it is also accepted that pupils show less interest in considering the unseemly teaching strategies used in the classroom. They are not presented to an enjoyable learning environment.

Owing to this matter, as it is also difficult to address the individual pupil differences, learning styles, diverse backgrounds, multiple abilities, and even diverse mother tongues and cultures, it is crucial that teachers adapt their teaching methods to match the pupils' needs. As mentioned by Choudhary (2016), literature appeals to learners of different styles and encourages thinking and purposeful learning. From that, teachers are encouraged to participate further in collaborative initiatives and gain expertise through an international forum where educators around the world are allowed to discuss innovative approaches to teaching. Also, the study of literature offers a range of opportunities for English language teachers to improve the content of their language classes. Hence, this research aims to discover the effectiveness of utilising the language-based approach in enhancing pupils' interest in children's literature in the Malaysian ESL classroom. Besides, it aims to see literature as tool to encourage pupils' interest in learning literature.

As literature offers various advantages to the learners including improving the reflective and purposeful learning of the learners as well as exposing them to cultural awareness and critical thinking, a suitable literary text should be arranged that illustrates the characters, plots, themes, and much more. Similarly as what had been proposed by Barnett in the year 1989, "the essence of an authentic text is that it offers voluminous focal points for pupils such as (1) enjoying the role of a motivator for learners, (2) supplying real context for learners, (3) spreading the target language culture, and (4) preparing learners for the outside world." Furthermore, in a literature study, teachers additionally need to include the skill of critical thinking as it is very fundamental in the account that it is needed for practical purposes. In any case, the exercises planned as a classroom activity must above all conform to the aim of training the pupils to be student-centric and autonomous. The researcher chose a languagebased approach as a tool to measure the pupils' understanding and interest. The languagebased approach responds to the needs of language students in literature study: they gain the ability and methodology to encourage text exposure and develop awareness to various genres so that they can appreciate a piece of literature that is significant to their lives. This approach also suits students ' needs to learn a language better; they communicate in English to improve their language skills, build the appropriate collaborative work skills and become active participants in the learning. All educators believe the language-based approach is empowering because it helps students navigate a text, enhances the enjoyment and interest of their literature, improves their autonomy, and enhances their English learning.

\section{The Teaching of Literature in Malaysia}

The primary school system in Malaysia explicitly sets out different kinds of schools namely national schools (SK) and national-type schools (SJK). SK uses the Malay language as the main instruction medium while SJK uses Mandarin or Tamil instead. Not only in the form of 
language but also in the time allocation of each class period have these schools contrasted. Due to the incorporation of extra language in the curriculum, the time apportioned for the teaching of all subjects in SJK is reduced. As cited by the Ministry of Education (2012), time dispensed for English in SK is 300 minutes and it is $\mathbf{1 5 0}$ minutes for SJK. Concerning the extra language in SJK, the time allotted is 360 minutes. Consequently, many English teachers in SJK are worried about the teaching and learning hours for English in SJK which is by all accounts lacking.

However, in the augmentation of English literature, the government has made a lot of efforts to draw pupils into learning and participating in classroom activities, as well as to give them a better overview of the literature value in education just like the other components of this subject. Additionally, the conceptualization of Memartabatkan Bahasa Malaysia Memperkukuh Bahasa Inggeris (MBMMBI) is also to be experienced where the implementation of literature components is also to be exact in the Language Arts. Language Arts has the propensity of helping the pupils to enact their enthusiasm as it works with numerous intriguing teaching and learning strategies, for instance, incorporating short stories, poetry, and music into the learning environment.

Taking a gander at the discrepancy in the literature teaching situation in Malaysia, it is important to take into account the use of approaches that will be utilised in the classroom. Teachers need to prepare and incorporate an assortment of teaching strategies that often look at the English language proficiency level of each particular group of pupils. Simultaneously, the objectives of this curriculum need to be upheld and accomplished since the integration of literature components into the national English curriculum has received substantial support from a number of parties, it is encouraged that the designs of literature classroom activities are in the position to promote the academic development of the pupils, their critical thought and interest in literature (Agee, 1998). It is along these lines that English teachers need to ensure that pupils get engaged in the classroom activities that help them to do their own problemsolving. Thus, that responds to why they need to prepare teaching materials to teach literature creatively.

\section{History of Literature Teaching in Malaysia}

Decades ago, English language teaching was greater probable to concentrate on communicative skills and particular practical and functional purposes. There has been several method projects that have taken language used as the main concern of teaching and learning activities of social contexts. Owing to this matter, space for creativity and literature in language context was seen as insufficient. In any case, during the 1980s, a striking recovery of interest in literature has risen. Literature teaching and learning with regards to Malaysian education appears to have a place in the context of the English language. Claims made by past researchers which calling attention to the possibility that literature could be more impressive in the classroom setting, and that literature teaching and learning materials were exceptionally regarded as valuable resources. As the year passes by, literature began to be regarded as one component to developing pupils' language due to teachers' points of view expressing that this source of language input ought not to be deserted. 
Continuing to the year 2004, Malaysia's Curriculum Development Center has launched a new curriculum known as the Children's Contemporary Literature. This programme contributed massively to the use of literary genres in primary schools in Malaysia. Furthermore, it is also intended to involve a literature component into English studies as an intense reading lesson, which is acknowledged as one of the resources that can improve on pupils' proficiency in this language. In Malaysia's education system, the government has lifted English as compulsory to be taught and learned in primary and secondary schools as it is in like manner functioning as a second language in this country. This likewise clarifies the reason why the government considers this component as fundamental because they believe that any literature program conducted in any country can contribute to the understanding of the pupils, particularly in the aesthetic elements of the language content. Moreover, they also believe that literature will help foster a positive atmosphere in the classroom. Thus, with the presence of the literature component, the Ministry of Education has begun setting its targets in English language teaching.

\section{Contemporary Children's Literature (CCL) Program in Malaysian ESL Classroom}

As the English literature classroom in Malaysia undergone various phases, this likewise witnessed the ups and downs and the other way around in the curriculum system. Hence, the Malaysian government has by and by coming out with a new policy which is Malaysian Education Blueprint 2013-2025. This blueprint points out the significance of literature in English subject clearly. Much the same as included by Ganakumaran (2003), literature reading materials about different cultures and world outlooks can create their personal development, and expand their world view.

Besides, the Government launched the Children's Contemporary Literature Program in the year 2003. January 2004 witnessed the execution of this program by the Curriculum Development Centre of Malaysia. Starting with all Year 4 primary school pupils, the selected texts in the form of storybooks are designed to suit all pupils' levels of proficiency in English regardless of their level division. Six prescribed text was used in literature classes listed by the Curriculum Development Centre, followed by Year 5 in 2005 and Year 6 in 2006. These texts are used in different nation-states in all primary schools.

This intensive reading program enables the pupils to read, thus comprehend the issues highlighted in the text and the literature components highlighted a minimum of two books every year. Owing to this fact, the introduction of Children's Contemporary Literature in Year 4, 5 , and 6 is regarded as a help to make the pupils understand the world outside them; cultures, beliefs, and ways of life. This target can moreover aid them to develop emotionally and intellectually. Hence, this can be seen through the activities of intensive and shared reading. The government also claims that after their first three years of learning primary education, pupils should have an overview, early beginning as well as a foundation in literature. English teachers are therefore relied upon to advocate for a reading culture that reaches beyond the walls of classrooms. This is to guarantee that children's literature is not merely on papers in the classroom. 


\section{Literary Text for Year 4 Pupils - The King of Kites}

With the aid of the language-based method, the researcher uses a literary text The King of Kites throughout the research as the teaching and learning materials combined with various activities. The King of Kites is a short story that is used in the CCL program particularly in Malaysian primary schools for year 4 pupils. As this literary text is the requirement in the ESL classroom, it is easier to implement any activities related to this short story. Moreover, this story offers sufficient literature elements such as setting, plot, conflicts, characters, points of view, and themes. It also provides pupils with other moral values like we should learn to be appreciative and grateful for what we have in life. Additionally, it also allows pupils to express their thoughts and points of view and understand other people's cultures. As reflected in the short story, the writer portrayed the Indian tradition of kite flying, particularly during festivals. As far as sharing the same activities is concerned, teachers should encourage pupils to relate this kite flying activity as what they have in Johor, the southern part of Malaysia where kiteflying festivals will be held annually. Pupils can relate these cultures and they can comprehend the content of the text better.

\section{Purpose}

This study aimed to explore the effectiveness of utilising the language-based approach in enhancing pupils' interest in children's literature in the Malaysian ESL classroom. This research, along these lines, aimed to show the effectiveness of language-based activities associated with the chosen literature text namely the King of Kites as tools to encourage pupils' interest in learning literature. Sufficient time was allotted for initiating desired pupil responses and providing advice and support on any work-related learning activities.

\section{Literature Review \\ Models of Teaching}

According to Carter and Long in the year 1991, in teaching literature to the English second language learners, three models work differently to assist the classroom activities. Such models explain the use of literature in classroom practice. These models also contrast to the text emphasis. Therefore, the utilisation of literary text in the classroom practice relies upon how teachers choose and implement the model.

\section{- $\quad$ The Cultural Model}

This model is more a part of the traditional practice of teaching literature. There will be the inclusion of some aspects, namely social, political, and literary as well as a historical context of a particular text and these aspects need to be identified by the pupils. This needs borderless thought and ideas when reading the literary text that can be conveyed by the pupils as reading would, in general, be focused on obtaining information. After reading, the pupils should be able to understand different cultures and practices which have a place with other groups and relate it to their own. Likewise, this model presents the idea of teacher-centered. It thus needs the teachers to transmit a major and significant input to the pupils. 
- $\quad$ The Language Model

The Language Model is the most widely recognised approach in the ESL classroom. Pupils who are introduced to this model will be consistent and meticulous in accessing any texts. In this approach, it is suggested that teachers use a variety of language teaching techniques, including sketch, jumbled words or sentences, essay writing, and many more. These activities are designed to analyse literary texts with a view to achieving linguistic objectives. As indicated by Savvidou (2004), pupils should use the text with the ultimate aim of linguistic practice rather than researching literature to obtain facts and information. In this manner, literature is mechanistically used to produce a set of language tasks. This approach similarly aims to incorporate language and literature more prominently where pupils will, by and large, grow in language skills through the delivery of language activities.

- $\quad$ The Personal Growth Model

This model is more likely to focus on individual development. This also includes the integration of their feelings just as individual traits. It likewise centers on the literature itself that plays a role as a material and teaching aid, not on a literature study to make one improve in language learning. By utilising this approach, pupils can look for the chance to react to the literary text, topics, and conflicts, and interact with their personal life experiences. As Carter and Long (1991) have explained, this model allows pupils to develop their comprehension of ideas and involves personal involvement with the reading of the literary text. It can make literature accessible to all pupils. Through reading, pupils will display the text's need for pedagogical values that will help them improve their critical awareness and to become a critical reader.

Considering that this model aims to inject a continuous love and appreciation of literary texts, it encourages pupils to engage in literary text reading. It additionally urges pupils to appreciate and value literature outside the classroom thus, inspiring and supporting pupils in the class of literature.

\section{Approaches in Teaching Literature}

Different models have distinctive approaches. An approach proposed by Anthony (1963) is a collection of suppositions that incorporate the essence of language as well as teaching and learning. Added by Brown \& Lee in the year 2015, an approach is a mindset that language is close to the essence of language learning. The practicality of all natures is often integrated into educational settings. The cited definitions demonstrate the influence of an approach to the teaching strategies. As for this study, the researcher decided to use the language-based approach as a significant highlight.

\section{- $\quad$ Language-based}

This approach provides pupils with the ability to access a text systematically and methodically just like in Carter and Long's suggested language model. As designed to help pupils improve their language skills, the literary used in this approach is lifted. It 
can well be finished by giving the pupils with adequate knowledge of the language and connects them to the language aspects in depth. Mechanistically, therefore, literature can be used to expand the ideas of classroom activities such as creative writing, descriptive writing, sketch, and many more (Maley \& Duff, 2007). In the literature classroom, the emphasis was on the pupils, the process of reading, and the knowledge of the language (Too, 2007). In this manner, is it proved that the researcher's choice of using the language-based approach to attract the pupils to learn literature is solid and practicable.

- $\quad$ Literary Text - Short story

Different points of benefits can be gained through the teaching and learning of short stories, particularly in language classes. Many literary texts such as short stories are believed to improve both teaching and learning English skills. In addition, it will help to increase cultural knowledge, knowledge of linguistics, and much more. As Richards \& Rodgers (2001) wrote, if the teachers correctly use some short stories with the provision of quality text material in the classroom practice, it can contribute significantly to enhancing the degree of capability of the pupils. According to Young (1996), there were two benefits of having short stories in the classroom. The pupils tend to be critical thinkers to whom they are 1) engaging and decreasing the prevalence of pupils' anxiety, normal, familiar and enjoyable, and 2) integrating critical thinking issues in a way that is easily remembered.

Since short stories inspire pupils to read and solve the issues with the right approach and series of attractive language activities (Erkaya, 2005), pupils will not get irritated easily, so they are more interested to learn literature. As Hismanoglu (2005) quotes from the pedagogical advantages of short stories, there are eight key advantages which short stories 1 ) ease the reading tasks as it can be short and simple, 2) provide pupils with an overview of other communities' way of life, 3) demand additional focus and analysis, 4) offer an enticing world, 5) assist pupils towards innovation and creativity by thinking critically, 6) raise understanding of other cultures, 7) cure anxiety among pupils and 8 ) useful for multicultural settings on account of its universal language.

- $\quad$ Past Studies

A creative approach to teaching literature in Malaysia is very significant and necessary, based on the words through Brown \& Lee (2015). Therefore, the teaching of literature can be innovative with the guidance of creative practices that combine language-based and stylistic approaches as well as a discourse approach in present classroom practice. In addition, pupils' attitudes and actions towards literature as per Mercer \& Candlin (2001) will decide whether learning literature succeeds or fails.

Past scholars have incorporated the language-based approach into various researches. In integrating a language-based approach into literature classrooms, the text was chosen to be more enticing and captivating to be interpreted and used because 
it encourages pupils to analyse the text themselves in means of specific manipulation, transformation, experimentation, and dissection. This assortment of steps can draw in pupils to learn literature and reduce the lack of excitement. Using a language-based approach in the classroom may enhance activities and provide meaningful clarification of the text. In addition, pupils are shown to be highly motivated when they are introduced to what they enjoy, and this involves exposing them to literary texts for learning purposes (Khatib, Rezaei \& Derakhshan, 2011). Along these lines, attention should be given to the value of the appropriate approach with practical activities.

The creative activities that are incorporated in this approach will allow teachers to set a plan of teaching strategy. However, the teacher needs to adapt the activities designed to suit all proficiency levels in line with the text. The texts used in Malaysian ESL classrooms are essentially a collection of localised literature of which common fables, poems, and short stories are included. Localised literature, referring to Brock (1990), contains material, context, cultural expectations, circumstances, characters, vocabulary, and cultural references that are common to second language learners. A text related to the real-life situation will arouse the attention of pupils and, subsequently, they become more and more informed and motivated.

\section{Methodology \\ Research Design}

This primary research objective is to investigate the potential outcome of utilising the language-based approach to enhance pupils' interest in literature with the use of literary text The King of Kites. This research incorporates qualitative methodology and is in the case study form. As for the research methodology, the researcher employed a descriptive research methodology, and pre- and post-test were used as the first instrument and questionnaire as the second. There were 30 primary school pupils from Endau, Johor got selected randomly regardless of their academic background and they became the participants of this study after obtaining permission from the authorities. The names of the participants were not being exposed and they were only labelled as Participant 1, Participant 2, Participant 3, and so on. Right off the bat, the researcher identified the challenge of the lack of interest of pupils in the literature classroom and formed an action plan to decode the issue by introducing a languagebased approach. The researcher then put the planned action into effect and reported the data collected.

\section{Research Participants}

According to Taherdoost (2016), for each case of the population, a simple random sample implies that there is an equal probability of consideration in a sample. In this study, the researcher chose 30 primary school pupils from Endau, Johor as the participants based on basic random sampling. The pupils are 10 years old and vary in their level of proficiency. The major numbers of pupils were intermediate and others are in low. As they are native speakers of Malay language, they learn English as a second language. However, they only use English during English lessons in the classroom. 
Vol. 9, No. 2, 2020, E-ISSN: 2226-6348@ 2020 HRMARS

\section{Research Instruments}

As the pre- and post-tests were performed for primary data gathering purposes, this test involves the calculation of the interest rate followed by a post-test on the same measure (Salkind, 2010). For the test designed, both pre- and post-test provide the participants with 15 questions. The reason for providing 15 questions is to make it easier to classify the three groups of levels according to the marks. After two weeks of learning literature with the aid of the language-based approach, the participants were given another test which called a post-test. Except for arranging the items that were manipulated, the items used in both pre- and posttests were identical.

Another instrument used was a questionnaire. This questionnaire consisted of Yes-No items and was circulated to the pupils who were chosen as participants and examined in order to get their feedback on the teacher's approach to teaching literature. The questions concerning the interview were categorised and coded into two parts. Part A of the interview was adopted from Nordin (2011) and adapted. The items in this part consist of the participants' general background information. The second part of the questionnaire serves 10 statements relating to the topic of this study as well as the approach used. It was designed to get the details related to their past experience. The elements listed in the questionnaire are outlined in table 1 below.

Table 1: Questionnaire Items

\begin{tabular}{|c|c|}
\hline Item & Description \\
\hline \multicolumn{2}{|r|}{ Part A } \\
\hline $1-10$ & Participants' general information \\
\hline \multicolumn{2}{|r|}{ Part B } \\
\hline \multirow[t]{5}{*}{$11-15$} & I like to learn literature with language-based approach. \\
\hline & I think learning literature with language-based activities is interesting. \\
\hline & I understand the text using language-based activities. \\
\hline & I feel confident to learn literature after I learned it through language-based approach. \\
\hline & $\begin{array}{l}\text { I feel satisfied when I understand the text through language-based approach } \\
\text { activities. }\end{array}$ \\
\hline
\end{tabular}

The researcher took two steps to make sure the questionnaire session worked properly without hiccups. It also involves improving instrument validity. Before the questionnaire was answered, the researcher offered an explanation to assist the participants with the questions. Then, to ensure all questions have been answered, a quick analysis of the returned questionnaires is carried out. For this step, the participants were asked to do the analysis themselves but with guidance from the researcher. The researcher would make sure, after collecting the questionnaires, the number returned was exactly like what had been distributed. As asserted by Ary et al. (1990), to achieve a high validity, the researcher needs to make sure that the return rate is above $75 \%$. As for this study, the research received perfect return of the participants. 
Vol. 9, No. 2, 2020, E-ISSN: 2226-6348@ 2020 HRMARS

\section{Procedure and Data Analysis}

A group of 30 10-year-old primary school pupils has been sampled for this research. Before they started their lesson in the first week, the participants were given a pre-test in the form of the worksheet. The pretest acted as a screening method for testing their level of understanding and knowledge. After the pre-test was carried out, the participants were taught using the language-based approach. The learning process took about two weeks. In the fourth week, the participants sat for a post-test to evaluate their performance. The participants also had to complete a questionnaire survey at the end of the post-test.

Through and inferential statistics, the data collected were analysed later. The descriptive statistical approach used to evaluate pre- and post-test data were the frequency and mean whereas the inferential statistic method applied was paired sample t-test. This intends to answer the research questions. In comparison, data from the survey questionnaire were analysed by using a percentage descriptive statistic method.

\section{Findings}

For the findings, the researcher highlighted based on the research questions. There are two research questions in this study. The first question answers on the effectiveness of a language-based approach to increase pupils' interest in learning literature. The participants' scores in both pre- and post-test as the data were recorded and later analysed by using descriptive analysis namely frequency and mean. For the inferential analysis, the researcher used paired sample t-test through the Statistical Package for the Social Sciences (SPSS) software. These two measures relate in terms of frequency, mean, standard deviation, and significant value shown in table 2.

Table 2: Results of participants' scores in pre- and post-test

\begin{tabular}{ccccc}
\hline Test & N & Mean & Standard Deviation & Significant Value \\
\hline Pre-Test & 30 & 7.566 & 3.349 & 0.000 \\
Post-Test & 30 & 10.200 & 3.708 & \\
\hline
\end{tabular}

Referring to the table above, there was a significant increment in terms of participants' interest from both tests. We can also see the detail of a significant difference between the mean scores before and after learning using the language-based approach $(p>0.05)$. To strengthen this analysis, a chart of score level is provided as in Figure 1 below: 


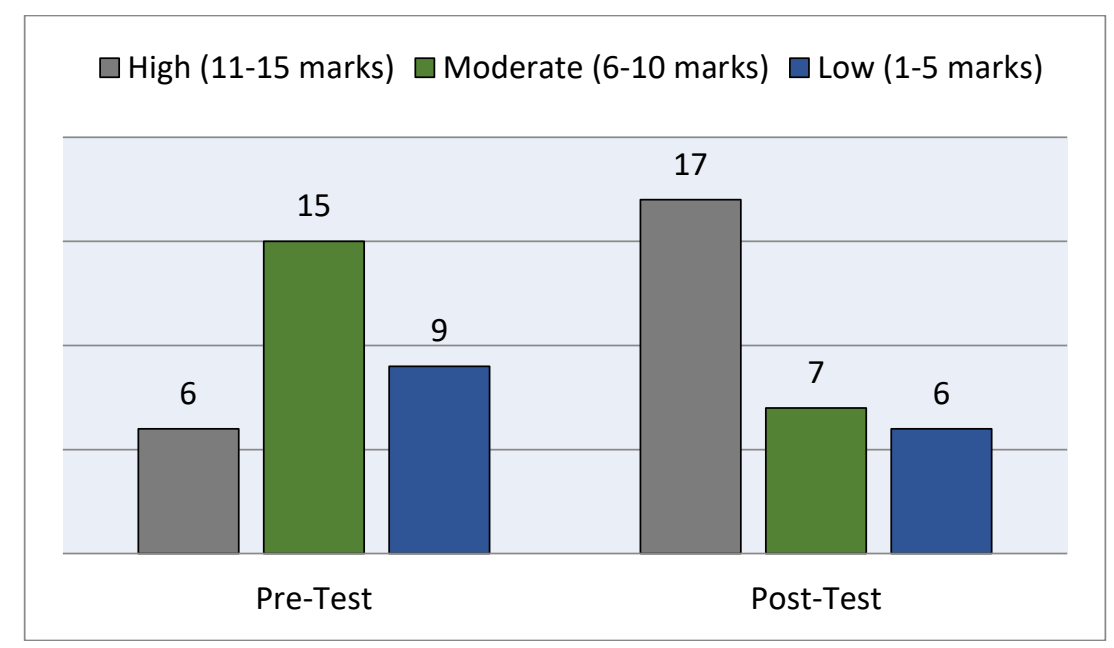

Figure1: Pre- and Post-tests score

According to the result shown, it is stated that in the post-test, more than half (17 out of 30) of the pupils achieved high marks compared to 6 out of 30 pupils during their pre-test. It is concluded as $56.7 \%$ of the participants scored higher in the post-test; thus, it proved that they performed better in literature learning with the assist of language-based approach. At the other side, $23.3 \%$ obtained moderate for the post-test, and $20 \%$ scored low in their post-test. With the score, there is a significant improvement illustrated to show the effectiveness of using the language-based approach in enhancing pupils' interest in learning literature.

The second research question was addressing whether the use of the language-based approach in learning literature can motivate pupils. The questionnaire items were then analysed, and percentage data were measured. Table 3 below provides the result:

Table 3: Participants' motivation in learning literature

No. Questionnaire Items

Participants'

Answers (\%)

1. I like to learn literature with language-based approach.

Yes No

2. I think learning literature with language-based activities is interesting.

$100 \% \quad 0 \%$

3. I understand the text using language-based activities. $100 \% \quad 0 \%$

4. I feel confident to learn literature after I learned it through language-based

4. approach.

$86.7 \quad 13.3$

5. I feel satisfied when I understand the text through language-based approach activities.

$100 \% \quad 0 \%$

The results in Table 3 showed the major numbers of participants possess high motivation in learning literature using the language-based approach. Many of the items earned a higher percentage than $80 \%$. In terms of attitude on using the language-based approach in 
learning literature, Table 3 showed that overall; more than $50 \%$ of participants have positive attitudes. Meanwhile, for satisfaction, all of them decided to feel satisfied when they understood the lesson. In general, most participants viewed this approach as an effective way to learn literature, and are excited to learn more in the future.

\section{Discussion}

From the analyses of pre- and post-tests and questionnaire surveys, it will, in general, be derived that there was a significant increment in pupils' performance while integrating the language-based approach in enhancing their interest in literature learning. Likewise, the pupils supported the use of a language-based approach and thought that it was motivating for them to learn literature. Some pupils, however, viewed their involvement in learning literature was obscure due to their inability of using the language. This should be an aspect that the researcher should consider in order to find out other initiatives for the pupils. This can be seen in favor of pupils with limited language-learning skills.

\section{Conclusion and Recommendations for Future Research}

The main concern of this paper was essentially how literature can increase pupils' interest in classroom teaching and learning session. Referring to the literature review texts from earlier researches, literature is considered to be one of the tools to assist the process of teaching and learning in the classroom. Furthermore, in situations where the critical use of literature to improve many skills such as language skills, critical thinking skills, and others, many accept that the use of an effective approach should be extended in the classroom.

In a classroom environment, pupils often demonstrate their interest and passion by getting involved in the classroom activities. Thus, it shows that the pupils are highly motivated as they are eager to complete the task given without any complaints. It thus indicates a positive sign where pupils are highly motivated as they are eager to complete the task they have been provided without complaints. The provision of good class materials by the teachers is therefore worthy of notice so that the pupils can fully participate without feeling restricted. The findings of this study showed that the use of the language-based approach is effective in enhancing pupils' interest towards literature particularly in The King of Kites. It can very well be seen that this strategy also provides tremendous potential to enhance pupils to display a positive attitude in the learning literature. In addition, most of the participants were able to display a positive attitude through the teacher's approach in the classroom activities.

As learning is the developmental aspect that involves changes in behaviour, skills, and knowledge resulting from practice and experience seeking quality education, the supposition of this study will be a huge contribution to extensive knowledge in the sense of pupils' achievement. The general result can be derived that there was a significant increment in pupils' performance while integrating the language-based approach in enhancing their interest in literature learning and beneficial specifically to the following: 
Vol. 9, No. 2, 2020, E-ISSN: 2226-6348@ 2020 HRMARS

School Administrators will gain insight into the best steps to help teachers navigate pupils with regard to the purpose of the study. Schools can likewise plan and provide teachers and the pupils with any required support including resources or teaching and learning aids necessary.

Teachers will be guided by the data on what to do with the pupils who are less interested in learning literature. The teachers should then be able to understand that certain pupils are having this dilemma and support them later on. This refers to professional teachers who have taken a 5 year TESL Bachelor in Elementary and Secondary Education course. Through the implementation of the approach in literature class, it will inject more creativity for many teachers and in specific cases, they can also think about some other approaches.

Pupils in this study are from a school in Mersing, Johor. In the education sector, they are perceived to be one of the key concerns next to secondary school students. The findings of this research in this study will encourage enlightenment and help the pupils in learning literature. The result will provide the pupils with the knowledge of learning literature with a new approach. This will also give the pupils recognition at the end of this study that studying literature is enjoyable and interesting.

Parents, just as teachers, who are specifically concerned with their children's education considering school performance and classroom achievement, will also understand why their children have less interest in learning literature from the data presented. The given data will allow them to devise any initiatives in order to ensure that their children are involving in classroom activities.

Future Researchers can take the result of this study as a guideline for further study on teaching-learning activities. The proposed ideas can also be used as reference data for dealing with new researches or for checking the validity of other similar findings.

\section{Acknowledgment}

The author appreciatively acknowledges the research participants for their involvement in this study.

\section{Corresponding Author}

Dr. Azlina Abdul Aziz is a TESL lecturer at the Faculty of Education, Universiti Kebangsaan Malaysia (UKM). She has an Ed.D in Teaching of English from Teachers College, Columbia University, U.S.A. Her research interests are in the Teaching and Learning of Literature and Teacher Education in TESL. She is interested in how literary texts and personal narrative may be utilised to help students to examine the social, cultural and political issues in a particular context. 
INTERNATIONAL JOURNAL OF ACADEMIC RESEARCH IN PROGRESSIVE EDUCATION AND

DEVELOPMENT

Vol. 9, No. 2, 2020, E-ISSN: 2226-6348 @ 2020 HRMARS

\section{References}

Agee, J. (1998). Negotiating different conceptions about reading and teaching literature in a preservice literature class. Research in the Teaching of English, 33(1), 85-124. https://www.jstor.org/stable/40171573

Anthony, E. M. (1963). Approach, method and technique. English Language Teaching, 17(2), 6367.

Ary, D., Jacobs, L. C., Sorensen, C., \& Razavieh, A. (1972). Introduction to research in education (2nd ed.). Library of Congress. https://ww2.odu.edu/ jritz/attachments/itrie.pdf

Barnett, M. A. (1989). More than meets the eye. Foreign language reading: Theory and practice. Center for Applied Linguistics; ERIC Publications. https://files.eric.ed.gov/fulltext/ED321555.pdf

Brock, M. N. (1990). The case for localized literature in the ESL classroom. English Teaching Forum, 28(3), 22-25. https://bibliography.lib.eduhk.hk/bibs/aa16253f

Brown, D. H., \& Lee, H. (2015). Teaching by principles: An interactive approach to language pedagogy (4th ed.). Pearson Education US.

Carter, R., \& Long, M. N. (1991). Teaching literature. Harlow, Essex; Longman.

Carter, R., \& Long, M. N. (1997). Teaching literature: Longman handbooks for language teachers. Harlow, Essex; Longman.

Choudhary, S. (2016). A literary approach to teaching English language in a multicultural classroom. Higher Learning Research Communications, 6(4). https://doi.org/10.18870/hlrc.v6i4.352

Erkaya, O. R. (2005). Benefits of using short stories in the EFL context. The Asian EFL Journal, 8, 38-49. https://www.asian-efl-journal.com/monthly-editions-new/benefits-of-usingshort-stories-in-the-efl-context/

Ganakumaran, S. (2003). Linguistic pathways to the study of literature in the Malaysian ESL context. GEMA Online Journal of Language Studies, 3(1), 16-36.

http://ejournal.ukm.my/gema/article/view/214/187

Hismanoglu, M. (2005). Teaching English through literature. Journal of Language and Linguistic Studies, 1(1), 53-66. https://www.jlls.org/index.php/jlls/article/viewFile/6/7

Khatib, M., Rezaei, S., \& Derakhshan, A. (2011). Literature in EFL/ESL classroom. English Language Teaching Journal, 4(1), 201-208. http://dx.doi.org/10.5539/elt.v4n1p201

Maley, A., \& Duff, A. (2007). Literature (2nd ed.). Oxford University Press.

Mercer, N., \& Candlin, C. N. (2001). English Language Teaching in Its Social Context: A Reader (1st ed.). Taylor \& Francis Ltd.

Ministry of Education. (2012). Malaysia Education Development Blueprint 2013-2025. Curriculum Development; Ministry of Education.

Nordin, M. (2011). Penilaian program mata pelajaran Vokasional (MPV) bagi bidang pertanian di sekolah menengah harian di Semenanjung Malaysia. Universiti Kebangsaan Malaysia Library. http://malcat.uum.edu.my/kip/Record/ukm.vtls003497442\#description

Richards, J. C., \& Rodgers, T. S. (2001). Approaches and methods in language teaching (2nd.). Cambridge: Cambridge University Press.

Salkind, N. J. (2010). Pretest-posttest design. Encyclopedia of research design, 1(0). http://dx.doi.org/10.4135/9781412961288.n331 
Savvidou, C. (2004). An integrated approach to teaching literature in the EFL classroom. The Internet TESL Journal, 10(12). http://iteslj.org/Techniques/Savvidou-Literature.html

Subarna, S., \& Ganakumaran, S. (2008). The incorporation of literature in the English Language Program for engineering Students: Learner interest and perception. 3L: Language, Linguistics and Literature, 14, 46-73. http://ejournals.ukm.my/3l/article/view/1019

Taherdoost, H. (2016). Sampling methods in research methodology; How to choose a sampling technique for research. International Journal of Academic Research in Management (IJARM), 5(2), 18-27. http://dx.doi.org/10.2139/ssrn.3205035

Too, W. K. (2007). Language-based approach. In Subramaniam (Ed.), Approaches to teaching literature: Theory and practice (pp. 33-49). Sasbadi Sdn. Bhd. file://C:/Users/User/Downloads/Too2007language-basedapproach.pdf

Young, A. (1996). Introducing critical thinking at the college level with children's stories. Journal College Teaching, 44(3), 90-93. https://doi.org/10.1080/87567555.1996.9925558 